\title{
Improving Quality of Halal Milkfish Gelatin by Cross-Link with Sucrose and Glutaradehid
}

\author{
K Mustami1, A Ahmad², A Ismail ${ }^{3}$, N Hamzah ${ }^{4}$ \\ Fakultas Tarbiyah dan Keguruan, Universitas Islam Negeri Alauddin Makassar ${ }^{1}$ \\ Fakultas Ushuluddin dan Filsafat, Universitas Islam Negeri Alauddin Makassar ${ }^{2}$ \\ Fakultas Kedokteran dan Ilmu Kesehatan, Universitas Islam Negeri Alauddin Makassar ${ }^{34}$ \\ \{muhkhalifahmustami@uin-alauddin.ac.id1, arifuddin.ahmad@uin-alauddin.ac.id², \\ isriany.ismail@uin-alauddin.ac.id ${ }^{3}$, nursalam.hamzah@uin-alauddin.ac.id $\left.{ }^{4}\right\}$
}

\begin{abstract}
One of the newest sources of halal gelatin is from fish scales, but it has low quality for pharmaceutical dosage form. Thepurpose of this studyis to improve the quality of milkfish gelatin by cross-link and halal analysis. Quality parameters are viscosity and swelling index. Gelatin samples were extracted by alkaline and acidmethod. The samples were divided into two large groups cross-link: gelatin and chitosan-gelatin. The sample was crosslinked with glutaraldehyde and oxidized sucrose. All samples were tested for identity using IR spectrophotometer, Oswald method for viscosity, and swelling index. Oxidized sucrose is made by reacting sucrose with sodium periodate. The halal study uses the treaser method where the materials that used and the manufacturing process are identified the possibility the existence of haram ingredients. The results showed creating cross link gelatin was successful as shown in the IR spectrum. The first group gelatin and the second group chitosan-gelatin had improved viscosity and swelling index quality. The second group has a better swelling index. Samples that cross-linked with glutaraldehyde had better viscosity and swelling index compared to samples with cross-linked oxidized sucrose. This shows that cross links have good polymeric properties. For the study of halal crosslink gelatin, samples materials have no critical point or possibility contaminated by haram material. Similarly, the manufacturing process also does not find a critical point that requires supervision. Based on this study, cross-linked gelatin has better quality than gelatin. The gelatin materials is also halal.
\end{abstract}

Keywords: Cross-link, Gelatin, Halal, Fish

\section{Introduction}

All products in Indonesia must be halal certified. Government through Law No. 33 at 2014 about Halal Products Assurances, states that all products that enter, circulate, and trade within the territory of Indonesia must be halal-certified. The implementation of this law must be in 2019, five years after it was decided. In addition to being a demand of the law, the increasing understanding of Islam, especially in the use of halal products, has made several industries that initially refused 
to have no choice except to accept the demands of Muslims as the biggest consumers in Indonesia. The emergence of controversy over the use of non-halal vaccines and the recent cases of pork contaminated noodles, shows an increasing awareness of the Muslim community about the use of halal products. In fact, several industries from other countries such as South Korea and Japan have developed their products to be halal certified. The aim of the developed halal product is being accepted as export commodities in Muslim countries.

The challenge of developing halal products of gelatin raw material is the source of material and quality improvement. Gelatin is one material that very popular in large products of food and pharmaceutical. Gelatin is the most widely used in candy products (soft candy) and capsule shells worldwide [1]. Gelatin is a mixture of polypeptides sourced from partial hydrolysis of collagen [2]. In the gelatin production, the main raw material that used is collagen which can be found in cattle and pigs [1]. The form of commercial gelatin is sheets, granules, or powder, mainly sourced from bones and skin of cattle, skin of pig, and, recently using pig bones [3, 4]. Other sources such as fish and poultry are very new and mostly processed to meet certain religious consumer groups $[5,6]$. However, due to the development of science and technology, food products rapid diversification, food products can use non-halal components to reduce production costs. In the market, pork gelatin is cheaper than cattle gelatin or other gelatin produced from halal sources [7].

Gelatin is a mixture of polypeptides that are made through collagen hydrolysis. Gelatin can be extracted from the skin, bones and skin of mammals such as pigs and cattle [6]. In addition, gelatin can also be made from fish $[8,9,10]$. Commercial gelatin is obtained from cows and pigs, where around $90 \%$ of the gelatin comes from pigs [11]. Gelatin has gelling properties such as gel strength and gelling time, melting temperature and viscosity which are suitable for use in food products such as soft candy. In addition, the surface behavior of gelatin (for example, the formation and stabilization of foams and emulsions, the nature of adhesion and destruction of dosage forms) plays an important role in food and pharmaceutical products [1,12]. One deficiency of fish gelatin is the low of gel strength. In the pharmaceutical field, the high gel strength required for the manufacture of hard capsule shells, above 200 brooms. Fish and chicken gelatin, as well as some gelatin from cattle, do not meet this requirement [4].

An alternative source for gelatin from waste products such as gelatin from fish scales will be a profitable alternative that can be considered. Indonesia is the second-largest country for fisheries production in 2016, with total production is over six million tons in 2014, making the potential is also large [13]. The highest production of fish is snapper, yellowfin tuna and skipjack for sea fish and milkfish and carp for cultured fish [13]. Gelatin from fish can be accepted by the Islamic community, and is also accepted with very little risk of being [14].

One deficiency of fish gelatin is the low rheological properties, gel strength and viscosity [15, 6]. In the pharmaceutical field, the gel strength properties for the manufacture of hard capsule shells is above 200 brooms [11, 1]. Fish gelatin does not meet this requirement. One method to increase gel strength is to make cross-link gelatin $[14,15]$. Gelatin can be cross-linked using certain ingredients, such as oxidized sucrose and glurataraldehyde, or combine with chitosan [16, 17, 18, 19]. Those substances will make gelatin bind to each other tightly through complex manufacturing. For this reason, we decide to make cross-link gelatin to improve the gelatin properties of fish, like to improve its viscosity and swelling index properties. Source of gelatin raw material is from industrial waste that can still be recycled. 


\section{Method}

\section{Materials}

The sample that used for this study was milkfish scales. The standard gelatin used is commercial gelatin (Brataco). Chitosan was purchased from Kawasan Industri Makassar (KIMA). Other ingredients such as $\mathrm{NaOH}, \mathrm{HCl}$, Glutaraldehyde, Sucrose and Sodium Periodate are purchased from Merck.

\section{Gelatin Extraction}

Procedures for extracting gelatin from fish scales through several stages, namely [20]:

a. Sorting

Fresh fish scales are cleaned by removing waste, meat, or fat. The sample is heated by hot water $\left(85-90^{\circ} \mathrm{C}\right)$ for 5 minutes to help washing fat from the sample and make it easier to remove scales from the skin [1]. Then, clean fish scales are dried.

b. Base and acid pre-treatment

Sample 50,0 gwas soaked with base solution ( $\mathrm{NaOH} \mathrm{1,0} \mathrm{N)} 350 \mathrm{ml}$ for 45 minutes at room temperature. After alkaline soaking, the sample is filtered and washed with distilled water 3 replicates. Then, the sample was soaked with acid solution $(\mathrm{HCl} \mathrm{1,0} \mathrm{N)} 350 \mathrm{ml}$ for 45 minutes at room temperature. After alkaline soaking, the sample is filtered and washed with distilled water 3 replicates. Pre-extraction with alkaline and acid aims to dissolve fat, proteins or other contaminants that are soluble in alkaline and acidic. Gelatin itself is difficult to dissolve in alkaline and acidic, but easily dissolves in neutral $\mathrm{pH}$. In addition, base and acidalso help soften the sample, making it easier to extract the gelatin [1].

c. Extraction

The soft sample was put into the extraction container and added distilled water $350 \mathrm{ml}$. The mixture is then neutralized with acid or base to neutralize $\mathrm{pH}$. Then, the mixture is heated at $90^{\circ} \mathrm{C}$ for 8 hours [11].

d. Drying

The concentrated liquid gelatin obtained from extraction was dried using heating in oven at $80^{\circ} \mathrm{C}$, generally for 72 hours. Then, dry gelatin is powdered.The effectiveness of extraction is determined by yield parameter of dry scales.

\section{Manufacturing cross-link gelatin}

a. Manufacturing oxidized sucrose

Sucrose 5.13 gram and Sodium Periodate 6.39 gram, dissolved in distilled water $50 \mathrm{ml}$ and let stand for 6 hours. The mixture then dried in oven at $70^{\circ} \mathrm{C}$.

b. Composing gelatin + chitosan + cross-linker.

Gelatin 10 gram was dissolved into $100 \mathrm{ml}$ of Chitosan solution $1 \%$ in acetic acid solution $1 \%$. Cross-linker material (glutaraldehyde or oxidized sucrose) with weights according to table 1 are dissolved in distilled water $10 \mathrm{ml}$. Compose the two solutions and stir until homogeneous. The mixture is allowed to stand for 24 hours. The mixture then dried at $70^{\circ} \mathrm{C}$.

c. Composing gelatin and cross-linker 
Gelatin 10 gram is dissolved in $100 \mathrm{ml}$ of distilled water. Cross-linker material (glutaraldehyde or oxidized sucrose) with weights according to table 1. Compose the two solutions and stir until homogeneous. The mixture is allowed to stand for 24 hours. The mixture then dried at $70^{\circ} \mathrm{C}$.

Table 1.Cross-link trial groups

\begin{tabular}{|c|c|c|}
\hline No & Group (Composition in gram) & Code \\
\hline 1 & Milkfish Gelatin & $\mathrm{Mi}$ \\
\hline 2 & Commercial Gelatin & $\mathrm{Co}$ \\
\hline 3 & Chitosan & $\mathrm{Ci}$ \\
\hline 4 & Milkfish Gelatin + Chitosan (10:1) & $\mathrm{MiCi}$ \\
\hline 5 & Commercial Gelatin + Chitosan (10:1) & $\mathrm{CoCi}$ \\
\hline 6 & Milkfish Gelatin+Chitosan+Oxidized Sucrose $(10: 1: 0,5)$ & MiCiSu 5 \\
\hline 7 & Milkfish Gelatin+Chitosan+Oxidized Sucrose $(10: 1: 0,25)$ & $\mathrm{MiCiSu} 2,5$ \\
\hline 8 & Milkfish Gelatin+Chitosan+Oxidized Sucrose $(10: 1: 0,1)$ & MiCiSu 1 \\
\hline 9 & Milkfish Gelatin+Chitosan+Oxidized Sucrose $(10: 1: 0,05)$ & $\mathrm{MiCiSu} 0,5$ \\
\hline 10 & Milkfish Gelatin+Chitosan + Glutaraldehyde $(10: 1: 0,25)$ & MiCiGu 2,5 \\
\hline 11 & Milkfish Gelatin+Chitosan + Glutaraldehyde $(10: 1: 0,1)$ & $\mathrm{MiCiGu} 1$ \\
\hline 12 & Milkfish Gelatin+Chitosan + Glutaraldehyde $(10: 1: 0,05)$ & MiCiGu 0,5 \\
\hline 13 & Milkfish Gelatin+Chitosan + Glutaraldehyde $(10: 1: 0,01)$ & MiCiGu 0,1 \\
\hline 14 & Milkfish Gelatin+Chitosan + Glutaraldehyde $(10: 1: 0,005)$ & MiCiGu 0,05 \\
\hline 15 & Milkfish Gelatin+Oxidized Sucrose $(10: 0,5)$ & MiSu 5 \\
\hline 16 & Milkfish Gelatin+Oxidized Sucrose $(10: 0,25)$ & $\mathrm{MiSu} 2,5$ \\
\hline 17 & Milkfish Gelatin+Oxidized Sucrose $(10: 0,1)$ & MiSu 1 \\
\hline 18 & Milkfish Gelatin+Oxidized Sucrose $(10: 0,05)$ & MiSu 0,5 \\
\hline 19 & Milkfish Gelatin+Oxidized Sucrose $(10: 0,01)$ & MiSu 0,1 \\
\hline 20 & Milkfish Gelatin+Glutaraldehyde(10:0,25) & MiGu 2,5 \\
\hline 21 & Milkfish Gelatin+Glutaraldehyde $(10: 0,1)$ & MiGu 1 \\
\hline 22 & Milkfish Gelatin+Glutaraldehyde $(10: 0,05)$ & MiGu 0,5 \\
\hline 23 & Milkfish Gelatin+Glutaraldehyde(10:0,01) & MiGu 0,1 \\
\hline 24 & Milkfish Gelatin+Glutaraldehyde(10:0,005) & MiGu 0,05 \\
\hline 25 & Commercial Gelatin+Chitosan+Oxidized Sucrose $(10: 1: 0,1)$ & $\mathrm{CoCiSu} 1$ \\
\hline 26 & Commercial Gelatin+Chitosan+Glutaraldehyde $(10: 1: 0,05)$ & CoCiGu 0,5 \\
\hline 27 & Commercial Gelatin +Oxidized Sucrose $(10: 0,1)$ & $\mathrm{CoSu} 1$ \\
\hline 28 & Commercial Gelatin+Glutaraldehyde $(10: 0,05)$ & CoGu 0,5 \\
\hline
\end{tabular}

\section{Quality Testing}

a. Organoleptic

The sample is observed in color on white paper.

b. Identification with IR Spectroscopy 
Samples were dried at $105^{\circ} \mathrm{C}$ for 5 hours. Dry samples were directly measured by IR spectral transmittance. Measurements were made at wavelengths of $400-4000 \mathrm{~cm}^{-1}$ Crosslink identification is confirmed by the changes in the IR spectrum of the sample.

c. Swelling index

Observed weights before (dry) and after incubation (swelling). Dry weight is the weight of the sample at $20^{\circ} \mathrm{C}$ to a constant weight. Swelling ratio is calculated using the formula

$$
=\frac{B_{s}-B_{d}}{B_{d}} \times 100
$$

Where $\mathrm{B}_{\mathrm{s}}$ and $\mathrm{B}_{\mathrm{d}}$ are gelatin weights at swelling and dry.

d. Viscosity

The sample weighed $6.67 \mathrm{~g}$ and then dissolved in $100 \mathrm{ml}$ distilled water at $70^{\circ} \mathrm{C}$. The gelatin solution cooled at $40^{\circ} \mathrm{C}$, then was measured for viscosity using calibrated-canon Fenske routine viscometer [21].

\section{Result and Discussion}

\section{Halal Studies of Cross-link fish gelatin}

Gelatin and its derivatives that produced in thisresearch are halal. The evaluation of halal is based on the principle in ushul fiqh, that state "all things are halal unless there is an argument for haramness of them." Materials that used in this study, such as water, sodium hydroxide, hydrochloric acid, chitosan, sucrose, sodium periodate, glutaraldehyde and commercial gelatin, are halal. The equipment is also certain to be free from najs, such as heavy, medium and light najs. Materials that are possibly to be haram are commercial gelatin and glutaraldehyde. Even though chitosan is a processed product, the process does not use haram substances, such as the shells of marine animals, hydrochloric acid and sodium hydroxide [22]. The commercial gelatin that used has a halal certificate by LP-POM MUI. Glutaraldehyde synthesis from acrolein and vinyl ethers, by Diels-Alder reaction or cyclopentene oxidation [23]. Acrolein is possibly sourced from burning glycerol, and it possibly sourced from lard. However, this chemical process has changed the character and chemical structure of the material so it meets the requirements of istihalah. Thus, glutaraldehyde is a halal material. In addition, if the synthesis pathway is through cyclopentene oxidation, the glutaraldehyde product is made from halal raw materials.

The focus of halal analysis for halal certification is to examine the possible halalness of each ingredient by detecting the critical point. Materials categorized as critical points are meat, animal derivatives, processed vegetable ingredients, industrial side-products of yeast, microbial products, and food additives (BTM) such as dyes, flavors, seasonings, aspartame sweeteners, vitamin premixes, coatings, emulsifying agents, antifoaming or others [24]. All materials are included in the critical point because it is possibly from haram material, or it is contaminated by najs and not holiness yet (thaharah process). Halal materials must be guaranteed not contain or contaminated with haram and najs materials, not just conjecture.

In accordance with the previous ushl fiqh principle, materials that included in the category of haram are pigs, khmar, carcasses (animals not slaughtered according to Shari'a), blood, animals with spurs or fanged animals, animals that live on land and water, and parts of the human body with different levels of najs [25]. Products, raw materials or processed raw materials that sourced from these materials are categorized as haram. In addition, if the material is solid or the equipment 
that used is contaminated with najs, the material or equipment must be purified with thaharah process. However, if the material is made from pigs, even though it has been thaharah processed, it is still categorized as haram. Some of haram ingredients are not najs, such as whole or parts of the human body and some animals that have spurs, but they are still haram to eat.

\section{Gelatin extraction}

Extraction method with alkaline and acid pre-treatment is effective to extracting gelatin from milkfish scales. The yield of extraction is $38.8 \%$, calculated against the weight of the scales that used. The extraction technique that used in this study refers to the research of Boran and Regenstein [20]with some modifications. This yield is greater than others yield of extraction from scales such as lizardfish $(10.7 \%)$, tilapia $(12.3 \%)$, and sea bream $(9.55 \%)[26,27,28]$. The milkfish gelatin is sheet-shaped, transparent in color and the smell of the fish has disappeared.

\section{Gelatin cross-link}

Materials commonly used as cross-linkers for gelatin are glutaraldehyde and oxidized sucrose. A cross-link reaction is formed between the aldehyde group ( $\mathrm{CHO}$ ) in glutaraldehyde and oxidized sucrose with the amine group $\left(\mathrm{NH}_{2}\right)$ in protein (lysine) and chitosan. The functional group that formed is imine $(\mathrm{N}=\mathrm{C})$. The bonds connect inter-macromolecular structures, such as inter-gelatin, inter-chitosan or gelatin-chitosan. This macromolecular structure is getting bigger so the viscosity is getting higher and the swelling index is getting lower.

This research succeeded in forming gelatin cross-link. The sign that a cross-link bond has been formed can be observed in the infrared spectrum in Table 2. Based on the reaction in figure 2, an imine group $(\mathrm{C}=\mathrm{N})$ is formed between gelatin and oxidized sucrose. This imine group is marked with a peak at wave number 1690-1640. The spectrum of the imine group is overlap with keto spectrum of the amide, which is 1680-1630. Mi spectrum at the peak 1658 showed the presence of amide groups of proteins. While the spectrum at 1688 of MiGu 0.05 and MiSu 0.1 shows imine groups that overlap with amide groups. This peak intensity is higher than the spectrum of Mi, and the shift of spectrum to 1688 is an indication of the formation of imine groups at MiGu 0.05 and MiSu0.1. Similarly, in a compose of gelatin and chitosan. The peak of 1639 with a slightly high intensity indicates the amide found in proteins and amines (1640-1500 $\rightarrow$ N-H bend). After crosslink with glutaraldehyde and oxidized sucrose, as seen in the spectrum of MiCiGu 0.05 (peak 1651) and MiCiSu 0.01 (peak 1658) also shows imine groups that overlap with amide groups, with higher intensity. This higher intensity is due to the formation of the imide group after cross-link, adding to the intensity of the previous peak. 


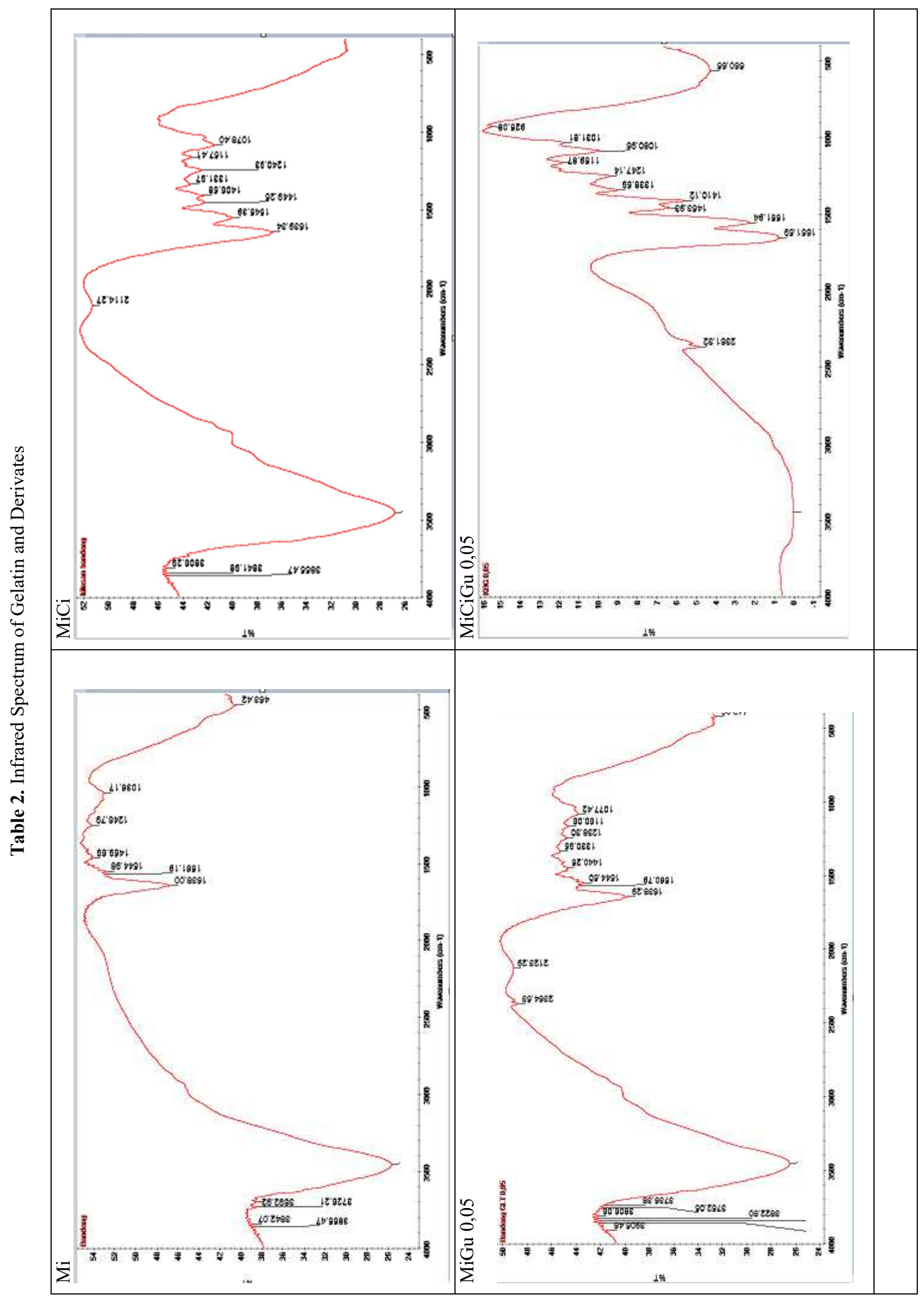




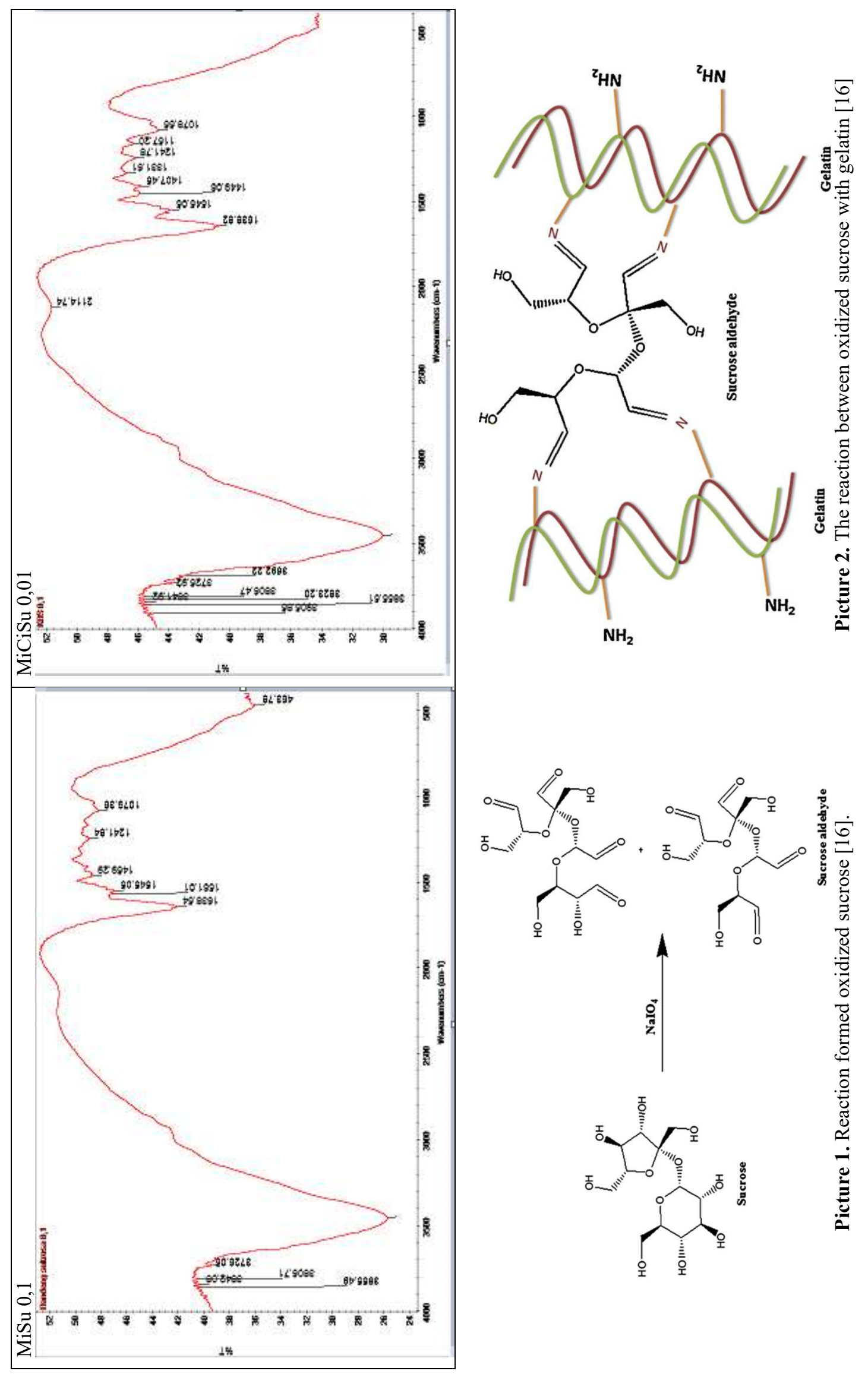


Table 3. Swelling index and viscosity of gelatin cross-link

\begin{tabular}{rllrr}
\hline No & Group Code & \multicolumn{1}{c}{ Organoleptic } & $\begin{array}{r}\text { Swelling index } \\
\%\end{array}$ & $\begin{array}{c}\text { Viscosity } \\
\text { cP }\end{array}$ \\
\hline 1 & Mi & Yellowish & nd & 2,314 \\
\hline 2 & $\mathrm{Co}$ & Yellowish & nd & 1,128 \\
\hline 3 & $\mathrm{Ci}$ & White & 470,74 & nd \\
\hline 4 & $\mathrm{MiCi}$ & Yellowish & 2745,65 & nd \\
\hline 5 & $\mathrm{CoCi}$ & Brownish yellow & 219,39 & nd \\
\hline 6 & MiCiSu 5 & Brownish & 268,06 & nd \\
\hline 7 & MiCiSu 2,5 & Brownish & 841,34 & nd \\
\hline 8 & MiCiSu 1 & Brownish & 1280,65 & nd \\
\hline 9 & MiCiSu 0,5 & Yellowish & 1602,745 & nd \\
\hline 10 & MiCiGu 2,5 & Blackish brown & 642,96 & nd \\
\hline 11 & MiCiGu 1 & Brownish & 699,68 & nd \\
\hline 12 & MiCiGu 0,5 & Brownish & 745,02 & nd \\
\hline 13 & MiCiGu 0,1 & Brownish yellow & 2173.63 & nd \\
\hline 14 & MiCiGu 0,05 & Yellowish & 2227,77 & nd \\
\hline 15 & MiSu 5 & Brownish yellow & 591,17 & nd \\
\hline 16 & MiSu 2,5 & Brownish yellow & 753,37 & nd \\
\hline 17 & MiSu 1 & Yellowish & nd & 4,954 \\
\hline 18 & MiSu 0,5 & Yellowish & nd & 3,137 \\
\hline 19 & MiSu 0,1 & Yellowish & nd & 2,991 \\
\hline 20 & MiGu 2,5 & Blackish brown & 879,41 & nd \\
\hline 21 & MiGu 1 & Brownish & 1160,03 & nd \\
\hline 22 & MiGu 0,5 & Yellowish & nd & 4,170 \\
\hline 23 & MiGu 0,1 & Yellowish & nd & 3,590 \\
\hline 24 & MiGu 0,05 & Yellowish & nd & 3,372 \\
\hline 25 & CoCiSu 1 & Brownish & 155,60 & nd \\
\hline 26 & CoCiGu 0,5 & Brownish & 388,26 & nd \\
\hline 27 & CoSu 1 & Yellowish & nd & 2,844 \\
\hline 28 & CoGu 0,5 & Brownish & & 2,475 \\
\hline
\end{tabular}

nd $=$ not determined

The cross-link gelatin showed improved viscosity and swelling index characters. Samples containing chitosan and cross-link gelatin with high concentration solutions are not soluble in water. Samples after added with water, only just swell. Because it is insoluble in water, this sample cannot be tested for its viscosity character. Conversely, in other samples, gelatin cross link is water soluble, and swelling index cannot be tested, but its viscosity is easily tested.

The higher the concentration of the cross-linker material, the smaller swelling index of the sample. Swelling index is a character that shows the ability of the sample to bind water. As a result of the reaction with the cross-linker, the area that initially can bind water becomes reduced. Some 
have reacted with cross-linker material. In addition, cross-link bonds make gelatin little swell due to the large number of bonds that formed.

The cross-link gelatin with oxidized sucrose is stronger than with glutaraldehyde, and conversely, the gelatin-chitosan cross-link with glutaraldehyde is better than with oxidized sucrose. Swelling index of gelatin with oxidized sucrose $2.5 \%$ is $753 \%$, while with glutaraldehyde $2.5 \%$ is $879 \%$. When compared to the standard of commercial gelatin ( $\mathrm{CoSu}$ and $\mathrm{CoGu})$ and milkfish gelatin, the cross-link gelatin is harder. For other samples, the gelatin-chitosan swelling index with glutaraldehyde $2.5 \%$ was $643 \%$, while with oxidized sucrose $2.5 \%$ was $841 \%$. Gelatinchitosan cross-link is stronger than gelatin cross-link.

Cross-link gelatin with glutaraldehyde has better viscosity than oxidized sucrose. The viscosity of gelatin with oxidized sucrose $0.5 \%$ was $3.137 \mathrm{cP}$, whereas with glutaraldehyde $2.5 \%$ was 4.170 cP. Viscosity of standard gelatin CoSu $1 \%$ is 2.844 and CoGu $0.5 \%$ is $2.475 \mathrm{cP}$. Viscosity of gelatin that has been cross-linked is also better than fish gelatin that is not modified by cross-link. Viscosity of fish gelatin is $2.314 \mathrm{cP}$ and commercial gelatin is $1.128 \mathrm{cP}$.

This cross-link gelatin can be utilized in the pharmaceutical field. Cross-link gelatin that is not soluble in water can be used as a disintegrator for tablets and raw materials for hard capsule shells;whereas, water-soluble cross-link gelatin can be used as raw material for gel and jelly.

\section{Conclusion}

Gelatin from milkfish scales can be improved its viscosity and swelling index characteristics, thus increasing the quality of milkfish gelatin. The method is cross-linked with oxidized sucrose and glutaraldehyde, with or without combination with chitosan. All materials that used in the process of making gelatin and cross-link gelatin are halal.

\section{Acknowledgement}

Thanks to the Ministry of Religious Affairs of The Republic of Indonesia and State Islamic University of Alauddin Makassar for the research grant, "Pengembangan Nasional" cluster, 2018.

\section{References}

[1] H. G. Reinhard Schrieber, Gelatine Handbook, Wiley-VCH Verlag GmbH \& Co. KGaA, 2007.

[2] C. Xian-Long, W. Feng, X. Xin-Yue, Z. Ying-Yong, S. Yan, L. Wei , Z. Ping , M. Shuang-Cheng, T. Shou-Sheng and L. Rui-Chao, "Identification of five gelatins by ultra performance liquid chromatography/time-of-flight mass spectrometry (UPLC/Q-TOF-MS) using principal component analysis," Journal of Pharmaceutical and Biomedical Analysis, vol. 62, pp. 191-195, 2012.

[3] L. O. S. W. F. Sandra Hermanto, "Differentiation of bovine and porcine 
gelatin based on spectroscopic and electrophoretic analysis," Journal or Food and Pharmaceutical Sciences, vol. 1, no. 3, pp. 68-73, 2013.

[4] J. Irwandi , F. Faridayanti , . E. Mohamed, M. S. and C. M. Yaakob, "Extraction and characterization of gelatin from different marine fish species in Malaysia," International Food Research Journal, vol. 16, pp. 381-389, 2009.

[5] G.-E. Joaquín , M. P. , F.-M. Fernando and G.-G. M. C. , "Physico-chemical and film-forming properties of bovine-hide and tuna-skin gelatin: A comparative study," Journal of Food Engineering, vol. 90, no. 4, pp. 480486, 2009.

[6] R. B. Aasia A. Karim, "Fish gelatin: properties, challenges, and prospects as an alternative to mammalian gelatins," Food Hydrocolloids, vol. 23, no. 3, pp. 563-576, 2009.

[7] T. K. T. A. R. Amalia Widyaninggar, "Differentiation between porcine and bovine gelatin in capsule shells based on amino acid profiles and principal component analysis," Indonesian Journal of Pharmacy/Majalah Farmasi Indonesia, vol. 23, no. 2, pp. 104-109, 2012.

[8] A. A. A.-H. A. B. K. M. N. M. M. N. Mohammad Hani Norziah, "Characterization of fish gelatin from surimi processing wastes: Thermal analysis and effect of transglutaminase on gel properties," Food Hydrocolloids, vol. 23, no. 6, pp. 1610-1616, 2009.

[9] M. C. G.-G. P. M. Begoña Gimenez, "Storage of dried fish skins on quality characteristics of extracted gelatin," Food Hydrocolloids, vol. 19, no. 6, pp. 958-963, 2005.

[10] K. K. B. P. M. S. Ilona Kołodziejska, "Modification of the properties of gelatin from skins of Baltic cod (Gadus morhua) with transglutaminase," Food Chemistry, vol. 86, no. 2, pp. 203-209, 2004.

[11] GMIA, Gelatin Handbook, Gelatin Manufacturers Institute of America, 2019.

[12] Y. B. C. M. R. M. H. R. N. I. A. Nur Azira Tukiran, "Use of principal component analysis for differentiation of gelatine sources based on polypeptide molecular weights," Food Chemistry, vol. 151, pp. 286-292, 2014.

[13] "Indonesia Fisheries : 2015 Review," California Environmental Associates, 2016. 
[14] T. Huang, Z.-c. Tu, X. Shangguan, X. Sha, H. Wanga, L. Zhang and N. Bansal, "Fish gelatin modifications: A comprehensive review," Trends in Food Science \& Technology, vol. 86, pp. 260-269, 2019.

[15] L. Lin, J. M. Regenstein, S. Lv, J. Lu and S. Jiang, "An overview of gelatin derived from aquatic animals: Properties and modification," Trends in Food Science \& Technology, vol. 68, pp. 102-112, 2017.

[16] K. Jalaja and N. R. James, "Electrospun gelatin nanofibers: A facile crosslinking approach using oxidized sucrose," International Journal of Biological Macromolecules, vol. 73, pp. 270-278, 2015.

[17] G. S. El-Fek, G. M. Zayed, Y. A. Elshaier and F. M. Alsharif, "ChitosanGelatin Hydrogel Crosslinked With Oxidized Sucrose for the Ocular Delivery of Timolol Maleate," Journal of Pharmaceutical Sciences, vol. 107, no. 12, pp. 3098-3104, 2018.

[18] J. Martucci, R. Ruseckaite and A. Vázquez, "Creep of glutaraldehydecrosslinked gelatin films," Materials Science and Engineering: A, Vols. 435436, pp. 681-686, 2016.

[19] M. Nouri-Felekori, M. Khakbiz, N. Nezafati, J. Mohammadi and M. B. Eslaminejad, "Comparative analysis and properties evaluation of gelatin microspheres crosslinked with glutaraldehyde and 3glycidoxypropyltrimethoxysilane as drug delivery systems for the antibiotic vancomycin," International Journal of Pharmaceutics, vol. 557, pp. 208-220, 2019.

[20] G. Boran and J. M. Regenstein, "Optimization of Gelatin Extraction from Silver Carp Skin," Journal of Food Sciences, vol. 74, no. 8, pp. E432-E441, 2009.

[21] GMIA, Standard Testing Methods for Edible Gelatin, Gelatin Manufacturers Institute of America, 2019.

[22] H. K. No and S. P. Meyers, "Preparation and Characterization of Chitin and Chitosan-A Review," Journal of Aquatic Food Product Technology, vol. 4, no. 2, pp. 27-52, 1995.

[23] E. B. Whipple and M. Ruta, "Structure of aqueous glutaraldehyde," The Journal of Organic Chemistry, vol. 39, no. 12, pp. 1666-1668, 1974.

[24] LPPOM MUI, Panduan Umum Sistem Jaminan Halal, Lembaga Pengkajian Obat-obatan dan Makanan Majelis Ulama Indonesia, 2008. 
[25] M. Ali, "Konsep Makanan Halal dalam Tinjauan Syariah dan Tanggung Jawab Produk Atas Produsen Industri Halal," AHKAM : Jurnal Ilmu Syariah, vol. 16, no. 2, 2016.

[26] Y. Akagündüz, M. Mosquera, B. Giménez, A. Alemán, P. Montero, M. Carmen and Gómez-Guillén, "Sea bream bones and scales as a source of gelatin and ACE inhibitory peptides," LWT - Food Science and Technology, vol. 55, no. 2, pp. 579-585, 2014.

[27] C.-Y. Huang, J.-M. Kuo, S.-J. Wu and H.-T. Tsai, "Corrigendum to "Isolation and characterization of fish scale gelatin from tilapia (Oreochromis sp.) by a novel extrusion-hydro-extraction process" [Food Chem. 190 (1) (2016) 997-1006]," Food Chemistry, vol. 196, p. 1368, 2016.

[28] S. Wangtueai and A. Noomhorm, "Processing optimization and characterization of gelatin from lizardfish (Saurida spp.) scales," LWT - Food Science and Technology, vol. 42, no. 4, pp. 825-834, 2009. 